\title{
PROFISSIONALIZAÇÃO DOS PROFESSORES DE HISTÓRIA NO ANTIGO NORTE DE GOIÁS: ENTRE A FORMALIZAÇÃO E A REALIDADE DA DOCÊNCIA
}

\author{
Norma Lucia da Silva ${ }^{1}$ \\ Marieta de Moraes Ferreira ${ }^{2}$
}

RESUMO: Este artigo busca analisar o processo de profissionalização dos professores de História no antigo norte de Goiás por meio do estudo de caso da cidade de Araguaína localizada na região norte do Estado do Tocantins. Com base no estudo do perfil dos licenciandos do curso de História, implantado na cidade em 1985, e do perfil dos professores que lecionavam em escolas da rede estadual até 2010 , constatamos que a maioria dos professores buscava uma formação superior muito mais pela diplomação que pela qualificação propriamente e que as escolas, mesmo com a formação dos docentes na área específica de História, os mantinham como polivalentes, o que dificultava ainda mais sua profissionalização.

PALAVRAS-CHAVE: Ensino de História. Profissionalização de Professores. Norte de Goiás. Tocantins.

ABSTRACT: This article aims to analyze the process of professionalization of teachers of History in the north of Goias through a case study in the city of Araguaína, in the northern region of the State of Tocantins. Based on a study of the profile of

1 Doutora em História Social. Professora do Curso de História da Universidade Federal do Triângulo Mineiro.

2 Pós-Doutora em História. Professora do Programa de Pós-Graduação em História Social da UFRJ. 
undergraduates in the History course implemented in Araguaína, in 1985, and also of the profile of the teachers who taught in state public schools by 2010 , we found that most teachers were more concerned about obtaining a graduate degree than getting proper training, and also that, although these teachers had specific training in the discipline of history, they were hired by schools as "polyvalent teachers", that is, for teaching several disciplines, which created more obstacles to their professionalization.

KEYWORDS: Teaching of History. Professionalization of Teachers. North of Goias. Tocantins.

Este artigo analisa o processo de profissionalização dos professores de História no antigo norte de Goiás por meio do estudo de caso da cidade de Araguaína localizada na região norte do atual estado do Tocantins. O estudo foi realizado com base na análise de documentos institucionais (de ex-professores e exalunos) do Curso de História da Faculdade de Educação, Ciências e Letras de Araguaína (FACILA) relativos ao período de 1985 a $2002^{3}$, e documentos de professores que atuavam em escolas da rede estadual de ensino até 2010 , além de dados do Instituto Nacional de Pesquisas Educacionais (INEP) e de fontes orais.

Realizamos este estudo a partir do curso de História de Araguaína, por considerá-lo representativo da forma como se deu a institucionalização desse tipo de curso no interior ${ }^{4}$ do país. A cidade de Araguaína está localizada na região norte do estado

3 Os cursos criados pela FACILA, em 1985, foram incorporados em 1991 pela Universidade do Tocantins (UNITINS), criada pelo governo estadual, e, em 2002, pela Universidade Federal do Tocantins (UFT).

4 Neste caso, consideramos interior do Brasil as regiões mais distantes do eixo Rio-São Paulo e litoral nordestino, onde foram criadas as primeiras instituições de ensino superior, especialmente as regiões Norte e Centro-Oeste, onde (excetuando-se as capitais) só foram criadas instituições de nível superior a partir da década de 1980 , de acordo com dados do Instituto Nacional de Pesquisas Educacionais (INEP). 
do Tocantins, a 370 km da capital, Palmas. Até a década de 1970, antes da pavimentação da rodovia Belém-Brasília ${ }^{5}$, era difícil o acesso à cidade, assim como a toda região norte de Goiás. Com o advento da rodovia, Araguaína tornou-se um elo entre as regiões centro-sul do país e a região norte, atraindo investimentos em diversos setores, principalmente nos setores agropecuário e comercial. Atraiu também profissionais de diversas áreas (professores, médicos, advogados, dentistas), que a consideravam uma região promissora. Em poucos anos, a cidade passou a ser considerada uma capital regional, sobretudo nas áreas de saúde e educação. Com a criação do estado do Tocantins, em 1988, Araguaína passou a ser a cidade mais desenvolvida do estado e hoje só é superada pela capital, Palmas. Atualmente, a cidade tem uma população de cerca de 140 mil habitantes e sua economia gira, principalmente, em torno da agropecuária. Nos setores de saúde e educação, a cidade permanece sendo considerada um polo regional servindo de referência à região norte do estado, além da região sul dos estados do Pará, Piauí e Maranhão.

De acordo com dados do INEP, a abertura de cursos superiores no antigo norte de Goiás se deu de forma muito mais lenta que nas regiões Sul, Sudeste e nas capitais do Nordeste brasileiro. Enquanto nestas últimas havia um investimento relativamente grande na abertura de cursos - sobretudo pelo crescimento da população urbana - no interior isso não era observado. No da região norte de Goiás - atual Tocantins - as primeiras instituições de ensino superior foram criadas apenas em 1985 com a Faculdade de Educação, Ciências e Letras de Araguaína (FACILA ${ }^{6}$ ), em Araguaína, e a Faculdade de Filosofia do Norte Goiano (FAFING), em Porto Nacional.

5 Aconstrução da rodovia Belém-Brasília (BR 153) começou em 1958 e terminou no período da ditadura militar na década de 1970, quando a pavimentação foi concluída.

6 Os cursos da FACILA foram incorporados em 1991 pela Universidade do Tocantins (UNITINS), criada pelo governo estadual, e, em 2002, pela Universidade Federal do Tocantins (UFT). 
A FACILA foi criada pelo Decreto Estadual n².413, de 2 de outubro de 1984, iniciando seu funcionamento em janeiro de 1985 com um efetivo de apenas dois professores contratados para a Faculdade. Segundo o Decreto, o objetivo principal da Faculdade era "formar professores e especialistas para atendimento da demanda da região escolar do Sistema Estadual de Ensino" ofertando os cursos de Ciências, com Habilitação em Matemática, Geografia, História e Letras (GOIÁS, Decreto n. 2.413, 1984).

De acordo com o documento de reconhecimento do Curso (BRASIL, Parecer n. 000446, 19927) e com os depoimentos orais, até 1992 a FACILA funcionou sem nenhum acompanhamento ou avaliação do Ministério da Educação. As autorizações para mudanças na estrutura e funcionamento dos cursos eram dadas pelo Conselho Estadual de Educação e mesmo assim sem a preocupação de uma verificação in loco.

As condições de institucionalização da Faculdade e manutenção do curso de História nos primeiros anos nos permitem tomá-lo como exemplo da forma como ocorreu o mesmo processo no interior do país. Principalmente nas regiões Norte e CentroOeste, cujas distâncias da capital dos estados eram maiores (pela própria extensão territorial) e o deslocamento era dificultado pela grande quantidade de rios, matas e florestas e pela ausência de rodovias pavimentadas. Isso tudo fez com que a implantação de cursos superiores nessas regiões fosse dificultada, primeiro, pela escassez de profissionais qualificados para propor e estabelecer esses cursos e depois pelo pouco investimento dos governos que, normalmente, os implantavam de forma emergencial e precáriå ${ }^{8}$.

7 O primeiro documento de avaliação local expedido pelo Ministério da Educação foi o documento de reconhecimento do Curso datado de agosto de 1992. Trata-se do Parecer $n^{\circ} 000446$ da Câmara de Educação Superior (CESU) do Ministério da Educação (MEC).

8 Referimo-nos aqui ao fato de na maioria dos estados, principalmente das regiões citadas, somente após um aumento muito grande da população e da demanda pelo o ensino é que os cursos foram implantados, o que fez com que essa implantação ocorresse de forma emergencial. Para se ter uma ideia, em 1985, quando foram instalados os primeiros cursos da FACILA, havia na região (que na época pertencia ao estado de Goiás) apenas $5,12 \%$ de professores com 
Mesmo com todas as deficiências, a instalação da FACILA em 1985 representou o inicio do processo de formação, em nível superior, de uma parte considerável dos professores que atuavam na Educação Básica. De acordo com os depoimentos orais, havia entre os professores uma reivindicação de cursos superiores na região, ainda que muitas vezes não fosse visando, necessariamente, à qualificação, mas à melhoria do salário e das condições para aposentadoria. Assim, segundo eles, a formação superior significava muito mais a formalização da profissão, a ascensão na carreira e a garantia do emprego que a qualificação propriamente. Iniciou-se, então, conforme os depoimentos de alguns professores, uma "corrida" em busca da formação superior.

Segundo o professor M. F. havia uma grande movimentação nas escolas em relação à abertura da Faculdade na cidade. Para ele, os professores, em sua imensa maioria normalistas, tinham consciência de que a manutenção de seus cargos nas escolas dependia dessa formação. Assim, a "corrida" pela formação se dava também pelo medo que os professores, formados apenas no nível médio, tinham de perderem seus postos para profissionais formados vindos de outras regiões ${ }^{9}$ e pela pressão por parte dos gestores das escolas (públicas e particulares), principalmente depois da instalação da Faculdade, para que os professores buscassem uma formação superior.

O número de professores formados na década de 80 era baixíssimo. Quem chegava à cidade tendo formação, algum tempo depois era convidado para dar aula, porque já estava se exigindo isso. Nas escolas era necessário, mas os professores quase todos eram de ensino médio. Já aparecia essa exigência de ter formação superior, já se falava. Por isso que a Faculdade foi uma necessidade. Professores que vinham principalmente de Goiânia ou outros Estados vinham para Araguaína e vinham formados. Era uma ameaça. Lembro demais

formação superior para uma população de quase um milhão de habitantes, conforme dados de Aires (1998).

9 A finalização da pavimentação da rodovia Belém-Brasília (BR153) no final da década de 1970 intensificou a migração para as cidades, como Araguaína, que estavam localizadas às margens da rodovia. 
disso aí. O professor de ensino médio que tinha só o ensino médio se sentia ameaçado. Embora ele desse aula com tranquilidade, capacidade e tudo se sentia ameaçado, porque alguém chegava formado era contratado via Secretaria [de ensino], não havia concurso. Era contratado ia para a escola, ganhava a carga horária e se tornava o dono da carga horária. Enquanto o professor que trabalhava o tempo todo perdia a carga horária ou então ia para outra função, outra disciplina. [...] Todos os professores tinham que se formar, tanto particular quanto do Estado tinham que ter um curso superior para dar aula. Isso já começou a se tornar uma necessidade. Porque o Estado também não aceitou mais, e pressionava. (M. F.10, 2011).

O fato de a maioria dos professores possuírem apenas a formação de nível médio nos levou a investigar como teria sido essa formação e as funções desempenhadas por eles nas escolas.

O perfil dos alunos do curso de História da FACILA nos permite observar que, de fato, a maioria já possuía uma formação para o magistério e experiência docente.

\section{Gráfico 1 - Percentual de alunos da FACILA/UNITINS por tipo de formação secundária (1985- 1999).}

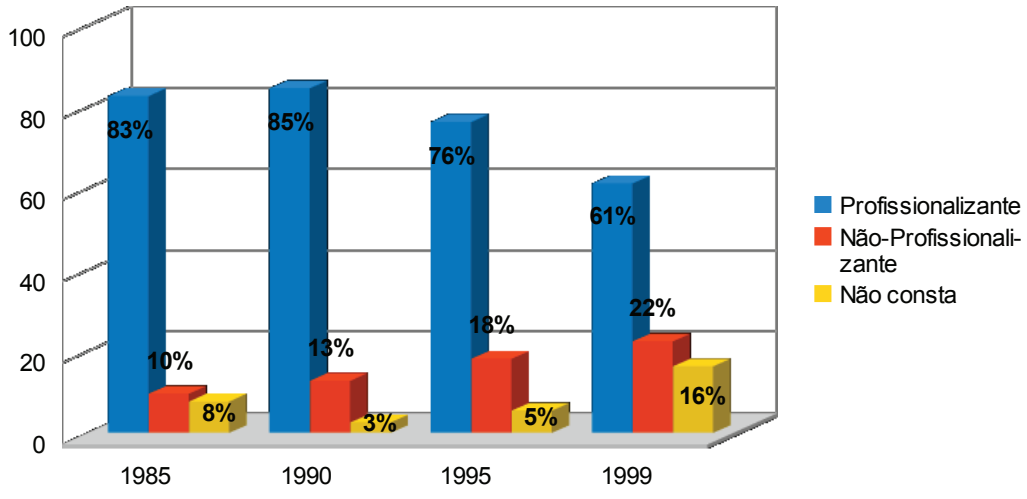

Fonte: UNITINS. Dossiês de alunos.

10 Foram colocadas apenas as iniciais dos nomes dos depoentes como forma de preservar as suas identidades. 


\section{Gráfico 2 - Percentual de alunos da FACILA/UNITINS por área de formação técnica secundária (1985-1999).}

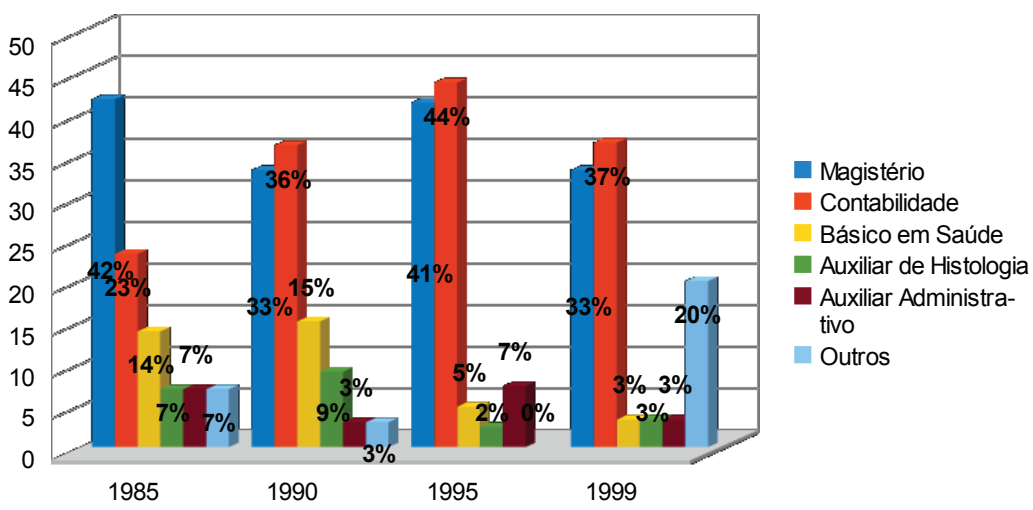

Fonte: UNITINS. Dossiês de alunos.

Em relação à formação secundária dos licenciados da FACILA a maioria deles havia realizado algum curso profissionalizante no Segundo Grau, o que é justificável, uma vez que os governos estaduais e federal incentivam esse tipo de formação.

Em Araguaína apenas uma escola privada oferecia o ensino não profissionalizante até a década de 1980. Seguindo essa tendência, em todos os anos observa-se um maior percentual de alunos formados nessa modalidade de ensino (83\% em 1985; $85 \%$ em 1990; $76 \%$ em 1995; $61 \%$ em 1999). Dentre os cursos profissionalizantes, os mais procurados eram os de Técnico em Magistério (42\% em 1985; 33\% em 1990; 42\% em 1995; e 33\% em 1999) e em Contabilidade (23\% em 1985; $36 \%$ em 1990; $44 \%$ em 1995; e $37 \%$ em 1999). Observa-se que esses dois cursos aparentemente competiam na preferência dos alunos sendo que o segundo ganhava terreno ano a ano. Os outros cursos mais procurados eram o Básico em Saúde, Auxiliar de Histologia, que era oferecido por uma única escola (Colégio Pré-universitário) e Auxiliar Administrativo. Havia ainda alunos formados em curso Técnico em Agropecuária, Comércio, Eletromecânica entre outros. 
Em linhas gerais, os alunos da FACILA/UNITINS, além da maioria ter formação secundária em Magistério ou Contabilidade, eram predominantemente do sexo feminino, maduros, com uma grande quantidade acima dos trinta anos de idade, uma boa parte casada e maioria oriunda do próprio estado de Goiás. Importante destacar essas características, pois esses alunos formariam o perfil dos primeiros professores de História, com formação superior, das escolas de educação básica da cidade e seu entorno, embora essa formação não tenha representado para muitos, sinônimo de uma profissionalização de fato.

As análises da documentação nos levaram a constatar que essa formação (nos cursos Técnicos em Magistério), no caso do norte de Goiás, foi realizada também de forma emergencial. Para se ter uma ideia, o déficit educacional da população entre 7 e 15 anos de idade no estado, em 1990, era de aproximadamente 200 mil crianças e jovens, correspondendo a mais de $50 \%$ da população desta faixa etária. Em 1994 a taxa de analfabetismo era de $38,36 \%$, uma das maiores do país (AIRES, 1998).

Além de não haver um número de escolas suficiente para atender a demanda, a formação daqueles que tinham acesso à escolarização era, muitas vezes, realizada por professores apenas com formação primária, pois o estado também era um dos que apresentavam a situação mais crítica em relação à formação de professores. Segundo dados de Maria Lourdes Aires (1998), dos 13.323 professores do Tocantins em 1996, apenas $1.217(9,1 \%)$ possuíam formação superior, destes 1.057 eram licenciados e 160 não eram licenciados. A grande maioria dos professores era formada ainda por normalistas (6.766), correspondendo a 50,8\% dos professores em exercício. Havia também um número grande de professores (2.089) com o ensino fundamental incompleto e $1.266(9,5 \%)$ de professores apenas com a formação de nível fundamental completa.

Os números relativos à educação no Tocantins podem parecer que a realidade era um tanto crítica, mas não se tratava de um caso isolado, na verdade, no caso da formação de professores a própria legislação permitia esse tipo de situação. Até a promulgação da Lei de 
Diretrizes e Bases da Educação (LDB) em 1996, a profissionalização dos professores não estava associada necessariamente à formação superior. Em todo o país, em especial no interior, a formação docente se dava em curso Magistério oferecido por escolas de Segundo Grau. Na realidade, o Magistério era uma chance real de um ofício e emprego para aqueles cujas chances de ter uma formação superior eram mínimas.

\section{A profissionalização dos professores de história}

Profissionalização quer dizer "ato ou efeito de profissionalizar(se)"; "tornar profissional"; "dar caráter de profissão a"11. Esta definição leva-nos a indagar sobre algumas questões. Para diversas profissões (engenharia, medicina, direito etc.) a profissionalização está associada à formação em curso superior. No caso da docência, fica a seguinte questão: os professores normalistas não são profissionais? Se sim, qual o papel da formação superior na profissionalização do professor?

Para Philippe Perrenoud, no caso da formação docente, "a profissionalização é uma expressão ambígua uma vez que pode 'insinuar' que, 'enfim', a atividade de ensino chegou ao status de profissão." (PERRENOUD, 2002, p. 10). Para ele, embora a evolução da profissão tenha se realizado a partir do século XIX, só gradualmente o ofício passou a ser objeto de uma verdadeira formação. Além disso, a profissão estava associada, sobretudo ao domínio dos saberes a serem ensinados. Segundo Perrenoud:

Desenvolvida para professores de ensino fundamental desde a criação das escolas normais, tal componente da formação continua tendo menos peso no caso dos professores do ensino médio e, em diversos países, continua sendo praticamente inexistente no ensino superior. Nesse sentido a profissionalização do ofício de professor poderia ser entendida apenas como um importante acréscimo à parte profissional da formação, ultrapassando o domínio dos conteúdos a serem ensinados. (PERRENOUD, 2002, p. 10).

11 Dicionário Houaiss da Língua Portuguesa. 
Para Perrenoud, todas as profissões são ofícios, o que não quer dizer que todos os ofícios sejam profissões. No caso anglosaxão, que ele analisa, o status de profissão está associado a ofícios bem específicos de acordo com os quais não se podem ditar aos profissionais seus procedimentos de trabalho e suas decisões. Teoricamente, segundo ele, um profissional deve ser competente para elaborar conceitos e executá-los: de identificar o problema, apresentá-lo, imaginá-lo, aplicar-lhe uma solução e, por fim, garantir seu acompanhamento, o que só poderia acontecer com saberes abrangentes, saberes acadêmicos, saberes especializados e saberes oriundos da experiência. Para ele, nas profissões das ciências humanas, prescreve-se menos que nas profissões técnicas, por isso, das primeiras exige-se um nível mais elevado de qualificação. Perrenoud ainda pontua que:

O grau de profissionalização de um ofício não é um certificado de qualidade entregue sem necessidade de exame a todos os que o exercem. Ele é mais uma característica coletiva - o estado histórico de uma prática -, que reconhece aos profissionais uma autonomia estatutária, baseada na confiança em suas competências e em sua ética. (PERRENOUD, 2002, p. 12).

Para Perrenoud, a formação inicial e continuada é um dos grandes propulsores da profissionalização dos professores, por ser um dos fatores que elevam o nível de competência dos profissionais, além de aumentar seus saberes e transformar sua identidade.

No caso do Brasil, o ofício de professor era considerado profissão enquanto o acesso à instrução escolar era restrito a alguns grupos sociais. Nessas condições, ser professor significava ter o domínio do saber e a responsabilidade de formar e tanto maior era a responsabilidade quanto maior era o nível no qual atuava. Com a mudança da legislação e a exigência da formação superior, o professor com formação primária ou secundária passou a ser visto como não-profissional uma vez que não era "formado". Assim, para além da profissionalização em si, havia 
uma necessidade da formação superior para alcançar um mínimo status profissional. No entanto, essa formação não significou para grande parte dos professores a profissionalização, a "construção e a atualização das competências necessárias para o exercício pessoal e coletivo da autonomia e da responsabilidade". No caso do Tocantins, a profissionalização era dificultada, como já foi dito, primeiro pelas condições de formação, que não promoviam a profissionalização integral, segundo porque as condições de trabalho, mesmo após a formação, impediam a formação plena do professor profissional.

O perfil dos ex-alunos da FACILA e da UNITINS reforça a ideia de um contingente grande de professores (que exerciam o ofício de professor sem formação superior) em busca da profissionalização (em curso superior). No entanto, nas condições em que funcionava o curso superior, ele não poderia oferecer uma profissionalização de maior qualidade em função das condições precárias do ponto de vista da infraestrutura e do quadro de profissionais recrutado para a sua implantação. Assim, nas entrevistas realizadas com ex-alunos do curso de História uma das perguntas que fazíamos era: "o que mudou na sua prática docente com a formação superior?".

O professor M. F. foi enfático em dizer que o curso não significou mudanças na sua prática como professor:

No meu modo de ver, e também de todos os colegas, não existiu algo novo. Continuamos da mesma forma profissional levando a sério, trazendo novidades para as salas de aulas, conforme já estávamos fazendo antes. Mas da faculdade trazendo algo novo não, em especial da minha turma. Eu falo da minha turma [...]. Porque a faculdade não tinha uma biblioteca, nós alunos fizemos a biblioteca que passou a acontecer, corremos atrás disso, compramos, fizemos bingo para trazer material, porque víamos, escutávamos lá, eles falavam para a gente: 'olha vocês corram atrás de material porque o curso de vocês não vai ser reconhecido se o MEC não encontrar aqui na área de História tantos volumes de livros de História'. Então nós mesmos, alunos, que corremos 
atrás. Tem livros lá que fomos nós que compramos, fazíamos bingo, juntávamos dinheiro, corríamos atrás de pessoas que podiam oferecer algum material. Depois que a gente saiu, depois de quatro anos, outras turmas vieram e continuou ainda difícil um bom tempo. (M. F., 2011).

Da mesma forma, a professora M. C. C. P. S. relata que não houve mudanças efetivas em sua prática. Para ela, aliás, havia uma pressão muito maior quando ela ainda não era formada, conforme seu relato:

Talvez a nível pessoal, não sei, a vaidade que eu era graduada, não é? Deve vir um pouquinho disso aí. Mas meu desempenho não mudou muito [...]. Em termos de prática de ensino, de atuação em sala de aula não alterou nada, pelo contrário, quando eu ainda estava cursando é que eu tinha toda a responsabilidade de me sair melhor. Eu tinha todo compromisso ali por eu não ser formada, eu tinha que dar o melhor de mim. (M.C.C.P.S., 2011).

Para a professora E. C. S. F., a sua prática cotidiana contribuiu muito mais para sua formação que o curso propriamente. Embora, ela considere haver uma bagagem de conhecimento maior com o curso superior. Além disso, considerava que o professor com formação superior deveria ser prudente na transmissão desses novos conhecimentos aos alunos. Segundo ela, havia essa preocupação também por parte dos coordenadores das escolas.

Eu acho que aprendi mais foi com o trabalho, o dia a dia mesmo [...]. Depois de formada eu me lembro do padre me chamar na sala dele e falar 'professora, agora a senhora terminou uma faculdade, mas a senhora lembre que os alunos que a senhora está ensinando qual é o nível deles'. Então, assim, o conhecimento da gente é um, o conhecimento que você vai trabalhar com o aluno de quinta série, sexta série, você tem que adaptar o seu, adaptar a linguagem para a linguagem que seja acessível a ele. Quando você termina a faculdade mesmo aos trancos e barrancos como foi a nossa, havia essa 
preocupação, assim, você terminou, você sabe mais, não é? Então você quer transmitir isso, mas então vamos cair na real 'são alunos que tem tantos anos tal'. Então tem essa necessidade. Hoje tem até um nome bonitinho, não é? Transposição didática. (E. C. S. F., 2011).

Maria Isabel de Almeida (2006), em artigo sobre a formação de professores, considera importante o reconhecimento de que a formação do professor está associada ao desenvolvimento pessoal, ao esforço de autodesenvolvimento, de trabalho sobre si. Revela um componente pessoal que surge da combinação entre o amadurecimento, a possibilidade de aprendizagem e as experiências vividas. Para ela é o próprio professor o articulador de suas metas, finalidades e valores. "É ele também o responsável último pela ação de formar-se, ou seja, pela capacidade e pela vontade de formar-se" (ALMEIDA, 2006, p. 177). Para ela, o professor, em sua formação, prepara-se para desempenhar as atividades inerentes ao seu campo profissional. A prática docente, no entanto, "não pode se resumir à aplicação de modelos, o que pressupõe que a formação deve requerer a mobilização de saberes teóricos e práticos" (ALMEIDA, 2006, p. 178-179).

Os relatos dos professores formados no curso de História da FACILA explicitam essa ideia da autoformação e do esforço próprio. Eles reconhecem a precariedade do seu curso e o quanto isso limitava as possibilidades de uma formação mais eficaz, no entanto, acreditavam que sua formação estava mais associada à sua prática que ao curso propriamente.

Nas palavras da professora A. A. P. S., "além de estar em uma Faculdade de História", que pela própria natureza do curso já suscitava questionamentos, ela e alguns colegas de turma "estudavam muito", "questionava algumas coisas". Também a professora E. C. S. F.: "aprendi mais com o trabalho, o dia a dia”. O professor M. F. reforça "nós mesmos alunos que corremos atrás".

Percebemos com os depoimentos orais que, para muitos professores, a formação no curso Magistério teria contribuído muito mais para a melhoria da sua prática docente que sua formação no curso superior. 
Essa valorização do curso Magistério pode estar relacionada à certa nostalgia por parte dos professores em relação a sua época de estudante, principalmente, porque a comparam à realidade atual das escolas. Para Clarice Nunes, as memórias dos professores contribuem para o entendimento de aspectos singulares do cotidiano escolar e permitem a passagem de uma memória pessoal para uma memória social e da educação, pois são lugares privilegiados de construção do entendimento. "São experiências intensas de exposição e autoconhecimento, de descoberta dos laços entre a memória pessoal e social" (NUNES, 2003, p. 142). Os relatos nos permitiram observar que os professores ao mesmo tempo em que supervalorizam o curso Normal, ressaltam as dificuldades da escola atual.

Não podemos fechar os olhos para os problemas enfrentados pelos professores hoje e a situação degradante de muitas escolas. No entanto, é preciso ponderar que as escolas de "antigamente" também tinham seus problemas e limitações. Os cursos Normais da região, por exemplo, eram bastante seletivos, uma vez que o número de vagas era reduzido em relação à demanda. Além disso, a quase totalidade dos professores desses cursos tinha apenas formação de nível médio. Muitos cursos eram ofertados de forma compacta e/ou à distância. Em relação a este último fator, se considerarmos que hoje, com todo o aparato tecnológico e de multimídia, a formação à distância apresenta problemas, podemos imaginar como teria sido naquele período, principalmente por se tratar de uma localidade distante dos centros de formação.

Assim, parece-nos que a supervalorização desses cursos por parte de alguns professores pode estar associada também ao fato de o curso Normal já Ihes render, naquela época, algum tipo de distinção profissional em um ambiente em que a imensa maioria dos professores era leiga. Vale lembrar que no estado do Tocantins em 1989 apenas 4\% dos professores tinham formação superior e menos de $50 \%$ tinham formação de nível médio, o 
restante possuía somente formação primária, como já destacamos anteriormente.

\section{O perfil dos professores de história da rede estadual de ensino de Araguaína}

A partir do levantamento do perfil dos professores que lecionavam História em escolas da rede estadual de ensino até 2010, buscamos compreender outros motivos que dificultavam o processo de qualificação desses profissionais. A pesquisa foi realizada em sete escolas estaduais de Araguaína nos arquivos ativos e inativos, que continham dossiês ${ }^{12}$ de professores que lecionaram História na escola.

A formação secundária em Magistério somou 51\% dos professores. O percentual de professores com curso secundário não profissionalizante é mínimo (8\%), o que pode ser explicado pela própria oferta de cursos de Segundo Grau na cidade que até a década de 1990 só era oferecido por uma escola particular.

Dos 156 dossiês analisados, 104 (67\%) foi possível verificar a área de formação dos professores, valores que nos permitiram chegar a algumas conclusões sobre sua profissionalização mesmo considerando apenas os dossiês que continham essas informações. Os outros 52 dossiês que não continham documentos sobre formação superior, pelas informações coletadas nas secretarias das escolas, são de professores com formação apenas de nível médio.

12 Os dossiês dos professores continham documentos pessoais, profissionais e de formação acadêmica de cada professor vinculado à instituição. 
Gráfico 3 - Área de formação superior dos professores de história das escolas estaduais de Araguaína pesquisadas em 2010.

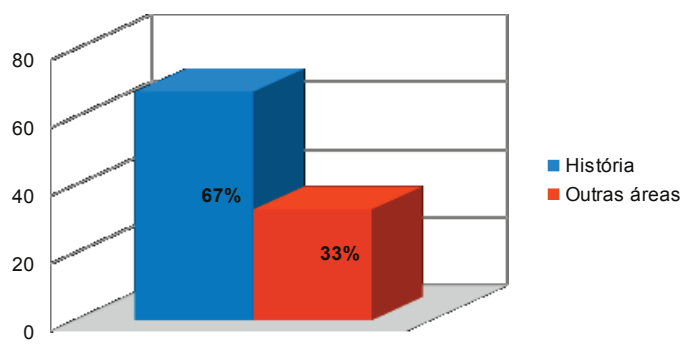

Fonte: Dossiês dos professores das escolas estaduais.

Entre os 104 professores com formação superior, 70 (67\%) eram formados em História e 34 (33\%), formados em outras áreas como Geografia, Letras e Direito, mas que lecionavam História. Dos 70 professores formados em História, 56 (80\%) eram egressos da FACILA/UNITINS, enquanto que 14 (20\%) eram formados por outras instituições.

Gráfico 4 - Instituição de formação superior dos professores de história das escolas estaduais de Araguaína pesquisadas em 2010

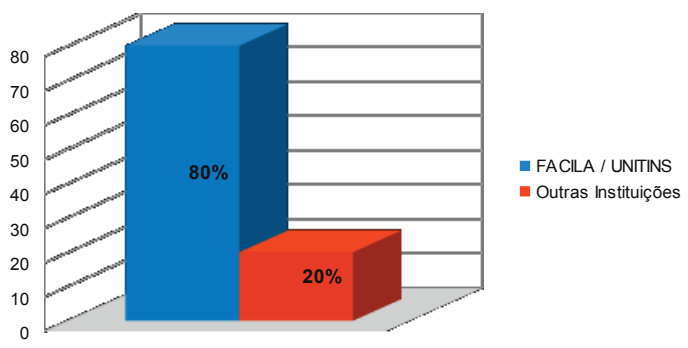

Fonte: Dossiês dos professores das escolas estaduais. 
Os documentos dos professores nos permitiram verificar que, mesmo após a formação superior em História, a maioria deles continuava lecionando disciplinas diversas, como faziam antes da formação, não havendo uma preocupação maior por parte dos gestores com a profissionalização nas escolas de educação básica. Além da formação deficiente, havia também uma precarização das atividades profissionais no interior das escolas que dificultava ainda mais a efetivação da carreira profissional na área de História.

Até recentemente ${ }^{13}$, a situação continuava bastante semelhante nessas mesmas escolas. Dos 21 professores que lecionavam a disciplina História, sete estavam fora de sala de aula, exercendo funções de coordenação pedagógica e reforço escolar, uma era formada em Letras, duas em Pedagogia e os demais lecionavam além da História disciplinas como Artes, Filosofia, Sociologia, Ensino Religioso e até Matemática.

A pesquisa nos permitiu constatar que, nas escolas de Araguaína e, ao que podemos inferir, em muitas da região norte do país, os professores com formação específica, mesmo após a formação superior, continuavam desempenhando as funções de polivalente. Nas escolas analisadas, não havia nenhum professor de História que lecionasse exclusivamente a disciplina História. Eles atuavam desde as séries iniciais, como professores primários, até o Ensino Médio, lecionando disciplinas de áreas completamente diversas de sua área de formação como Física, Matemática e Biologia. Inferimos que essa situação decorre, principalmente, dos seguintes fatores de igual importância: 1) da ausência de uma carreira docente vinculada a uma unidade escolar; 2) do currículo da educação básica que prevê cargas horárias bastante assimétricas entre as disciplinas; 3 ) do baixo número de professores com formação superior em algumas áreas do conhecimento; 4) da permanência da função de professor polivalente nas escolas da rede pública.

${ }^{13}$ A pesquisa nas escolas foi realizada nos anos de 2009 e 2010. 
No caso da ausência de uma carreira docente vinculada a uma unidade escolar, não há por parte do poder público um compromisso com a profissionalização dos professores nem com o desenvolvimento de um projeto educacional mais amplo que vincule os professores a uma determinada escola. Isso impossibilitaria o desenvolvimento de projetos de longo prazo e a qualificação voltada para realidade específica de cada escola. No Tocantins, assim como em outras localidades do Brasil, os cargos de gestão (incluindo diretores, coordenadores pedagógicos e supervisores) são cargos de confiança nomeados pelo Secretário de Estado. Isso leva a uma fragilidade da atuação dos profissionais nas escolas e a uma instabilidade no desenvolvimento de projetos, haja vista que, por mais bem-intencionados e competentes que sejam esses gestores, eles sempre podem ser exonerados dependendo dos interesses e alianças políticas em vigor.

Em relação ao currículo da educação básica, um dos principais problemas são as cargas horárias, que são bastante díspares entre as disciplinas, reservando-se à disciplina História um tempo relativamente curto se comparado à Língua Portuguesa e à Matemática, por exemplo. No caso do currículo do estado do Tocantins, na segunda fase do Ensino Fundamental (6 ao $9^{a}$ ano) há uma carga horária de História de três aulas semanais e no Ensino Médio duas horas-aula semanais. Os professores da rede estadual, cuja jornada de trabalho é geralmente de 40 horas semanais, têm que preencher 32 horas de efetivo exercício em sala de aula. Como a carga horária de História é reduzida, ele não consegue preencher sua carga horária apenas com a disciplina de História se quiser trabalhar em uma única escola. Assim, o que ocorre normalmente é que ele assume outras disciplinas para completar a carga horária mínima, assumindo muitas vezes disciplinas com as quais não tem afinidade. Assim, o quadro que se forma é que nem a disciplina de sua área de formação e nem as outras são ministradas com grande qualidade, pois, se já é difícil planejar e manter-se atualizado em sua própria área, imagine para uma área que não se teve formação nenhuma. $O$ que acaba ocorrendo é um prejuízo para a qualidade do ensino em todas as disciplinas lecionadas. 
Além do fator exposto acima e intrinsecamente relacionado a ele, é que no Tocantins há ainda um reduzido número de professores com formação superior em algumas áreas do conhecimento. Como vimos anteriormente, as primeiras licenciaturas foram criadas no estado apenas em 1985. De lá para cá, a situação do ensino superior tem mudado, mas alguns problemas ainda permanecem. Depois dos quatro cursos criados pela FACILA (História, Geografia, Letras e Matemática) naquele período, as outras áreas do conhecimento permaneceram desfalcadas. Somente em 2009, com a adesão da Universidade Federal do Tocantins ao Programa de Apoio ao Plano de Reestruturação e Expansão das Universidades Federais (REUNI) do Ministério da Educação (MEC), houve uma ampliação do número de cursos, com a abertura das licenciaturas em Biologia, Física e Química.

Por último, e não menos importante, há o fator da permanência da função de professor polivalente, mesmo para a segunda fase do Ensino Fundamental e Ensino Médio nas escolas da rede pública. Os professores até bem pouco tempo, formados apenas no curso Técnico em Magistério (de nível médio) estavam habituados a ministrar várias disciplinas no ensino fundamental e médio, seja para complementar carga horária, seja para cobrir as áreas desfalcadas. Em muitas escolas, mesmo havendo professores com habilitações específicas, os gestores não se empenham em cuidar para que eles atuem em sua própria área de formação. Prova disso, é que em várias escolas permanecem os professores atuando como polivalentes. Para se ter uma ideia, em uma das escolas pesquisadas havia três professoras formadas em História trabalhando na Secretaria e duas Pedagogas lecionando a disciplina História. Essa escola, não era um caso isolado.

Se no passado, o professor polivalente era uma questão de necessidade - por estar previsto na legislação e por não haver profissionais com habilitações específicas - na atualidade, trata-se muito mais de conveniências do que de necessidade propriamente. Conveniência dos governantes por interferir na vida escolar por interesses políticos; dos gestores por pensarem muitas vezes na facilitação de sua gestão em detrimento da qualificação 
dos professores e da qualidade do ensino; dos professores, que muitas vezes, por comodidade logística, preferem ministrar disciplinas que não são do seu domínio a completar carga horária da sua área em outras escolas.

Considerando-se que a profissionalização docente está também associada aos saberes e práticas por eles mobilizados, as condições nas quais esses professores têm realizado essa mobilização dificultam essa profissionalização, não pela falta de esforço ou empenho, mas pela quantidade de obstáculos que eles têm que enfrentar para o exercício da docência. Dificuldades estas que muitas vezes superam a questão da formação.

\section{Referências}

A. A. P. S. Depoimento oral [mar. 2011]. Entrevistadora: Norma Lucia da Silva. Araguaína, TO, 2011. 1 CD-ROM sonoro.

AIRES, Maria de Lourdes Fernandez Gonzalez. A formação de professores para o ensino fundamental e médio na Universidade do Tocantins - uma avaliação preliminar do período 1988-96. 1998. 190 f. Dissertação (Mestrado em Educação)-Universidade Federal de Goiás, Goiânia, 1998.

ALMEIDA, Maria Isabel de. Apontamentos a respeito da formação de professores. In: BARBOSA, Raquel Lazzari Leite (Org.). Formação de educadores: Artes e técnicas - ciências e políticas. São Paulo: Editora da UNESP, 2006.

BRASIL. Ministério da Educação (MEC). Câmara de Educação Superior (CESU). Parecer n. 000446, de agosto de 1992. Reconhecimento do curso de licenciatura plena em História da Autarquia Faculdade de Educação, Ciências e Letras de Araguaína. Disponível em: www.dominiopublico.gov. br/download/texto/cd003323.pdf>. Acesso em: 8 abr. 2009.

E. C. S. F. Depoimento oral [mar. 2011]. Entrevistadora: Norma Lucia da Silva. Araguaína, TO, 2011. 1 CD-ROM sonoro. 
F. M. Depoimento oral [mar. 2011]. Entrevistadora: Norma Lucia da Silva. Araguaína, TO, 2011.

GOIÁS (Estado). Decreto n. 2.413, de 2 de outubro de 1984. Cria, sob a forma de autarquia, a Faculdade de Educação, Ciências e Letras de Araguaína e dá outras providências. Universidade Federal do Tocantins, Campus Universitário de Araguaína, Coordenação do Curso de História, 2009.

M.C.C.P.S. Depoimento oral [mar. 2011]. Entrevistadora: Norma Lucia da Silva. Araguaína, TO, 2011. 1 CD-ROM sonoro.

NUNES, Clarice. Memória e história da educação: entre práticas e representações. In: BARBOSA, Raquel Lazzari Leite (Org.). Formação de educadores: desafios e perspectivas. São Paulo: Editora da UNESP, 2003.

PERRENOUD, Philippe. A prática reflexiva no ofício do professor: profissionalização e razão pedagógica. Porto Alegre: Artmed Editora, 2002.

Recebido em maio de 2015. Aprovado em janeiro de 2016. 